\title{
Comparison of Subjective Preoperative Experiences of Patients Before First- or Second-Eye Cataract Surgeries
}

This article was published in the following Dove Press journal: Clinical Ophthalmology

\section{Dorota Ługowska Joanna Konopinska (ID Zofia Mariak Iwona Obuchowska (1D}

Department of Ophthalmology, Medical University of Bialystok, Bialystok 15-276, Poland
Correspondence: Joanna Konopinska Department of Ophthalmology, Medical University of Białystok,

M. Sklodowska-Curie 24A STR, Białystok 15-276, Poland

Tel +48-857468372

Fax $+48-857468604$

Email joannakonopinska@o2.pl
Purpose: To compare the subjective preoperative experiences of patients undergoing their first- or second-cataract surgeries.

Patients and Methods: Consecutive patients undergoing phacoemulsification were asked to complete postoperative questionnaires evaluating their subjective preoperative experiences, including their emotional state, decision-making process, and opinions on the admission and examination processes, medical interviews, and quality of service. The obtained data were compared between patients undergoing their first (group I)- or second (group II)cataract surgeries.

Results: Two hundred patients (group I, 124; group II, 76) were included in the evaluation. Presurgical anxiety was more prevalent in group I than in group II $(55.7 \%$ vs $34.2 \%, P=$ 0.005). Fear was the major trigger for reconsidering the decision to undergo surgery, with $29 \%$ and $13.2 \%$ of patients in groups I and II, respectively, considering abandoning the operation $(P=0.016)$. The preoperative medical examination was reported to be sufficiently accurate by $66.1 \%$ and $80.3 \%$ of patients in groups I and II, respectively $(P=0.047)$, while $28.2 \%$ and $21 \%$ of patients in groups I and II, respectively, did not understand the information presented about possible complications of surgery $(P=0.039)$. Administration of eyedrops before surgery was uncomfortable for $71.4 \%$ and $68.4 \%$ of patients in groups I and II, respectively $(P=0.553)$, while $22.6 \%$ and $9.2 \%$ of patients in groups I and II, respectively, found repeated administration of drops to be highly uncomfortable $(\mathrm{P}=0.026)$.

Conclusion: Patients experienced greater anxiety before their first-cataract surgery than before their second-cataract surgery. Moreover, many patients from both groups did not understand the medical information provided by doctors regarding the surgery and its possible complications. The most unpleasant stage of preparation for cataract surgery was repeated administration of eyedrops.

Trial Registration: The study was registered on clinicaltrial.gov under the number NCT04327856.

Keywords: cataract surgery, anxiety, patients experience, presurgical fear

\section{Introduction}

Cataracts are the leading cause of blindness worldwide, and their surgical removal is currently the most frequently performed surgical procedure. ${ }^{1}$ This surgery takes place under topical anesthesia, and surgeons are able to communicate with patients throughout the procedure. Thus, patients are conscious, awake, and fully involved in the surgery. Anxiety directly related to the procedure is a well-known preoperative feeling for patients scheduled to undergo this surgery. ${ }^{2-5}$ Patients are usually 
concerned about their ability to maintain the eye still during the surgery or to properly cooperate with the surgical staff and remain immobile. Patients are also afraid of surgical pain and possible complications. Finally, enormous stress is caused by uncertainty regarding the outcome of the procedure and the degree of improvement in vision after surgery, as well as the fear of blindness. ${ }^{6}$

These feelings can be strong enough to force some patients to change their mind right before the procedure or to delay their registration to undergo the procedure, thereby worsening their vision and their quality of life. Patients with hypochondria and those prone to anxiety appear to show higher levels of preoperative anxiety. ${ }^{2,7}$ Previous surgical experiences, not necessarily related to ophthalmic procedures, may also increase or decrease patient preoperative fear. ${ }^{8}$ Fostering an appropriate doctorpatient relationship, ensuring social support, and providing sufficient knowledge about the patient's condition and treatment (eg, mentioning the safety of cataract surgery itself) can significantly reduce anxiety in patients. $^{7-9}$

Only a few studies have compared patients' preoperative feelings based on whether surgery was being performed in the first or the second eye. These studies have suggested that patients undergoing their second-cataract surgery tend to experience less anxiety and greater pain than those undergoing their first-cataract surgery. ${ }^{4,10-12}$ There is, however, a lack of detailed knowledge about patients' subjective feelings just prior to cataract surgery. Accordingly, in this study, we aimed to investigate patient feedback related to various aspects of surgical preparation and the waiting period before cataract surgery depending on whether patients were undergoing their first- or secondcataract surgeries. By so doing, we hope to improve patient management before cataract surgery in order to provide better service, motivate higher compliance rates, and create an improved quality of life, including reductions in associated anxiety.

\section{Patients and Methods}

This study was approved by the Bioethics Committee of the Medical University of Białystok in accordance with the Declaration of Helsinki. All patients provided written informed consent for the examination, received all the necessary information, and consented to publication of the obtained clinical data.

We prospectively identified consecutive patients undergoing routine phacoemulsification under topical anesthesia at the Department of Ophthalmology at the Medical
University of Bialystok between January and March of 2020. Patients who did not agree to participate in the study and those with severe deafness, senile dementia, or mental and anxiety disorders were excluded. Similarly, patients undergoing multiple procedures during a single operation and those with complicated cataract surgeries were also excluded. Following our routine practice, none of the selected patients received sedation in the preoperative period.

Patients were asked to complete a detailed questionnaire designed to recount their experience from the hospital admission process to the surgery itself. The questionnaires were administered immediately after the surgery in the postoperative recovery room, and assistance was offered in understanding and completing the questionnaire. Each patient was interviewed for 15 to 20 minutes. The survey included questions about (a) patient well-being on the day before surgery; (b) patient assessment of the hospital admission and surgical preparation procedures, including the pharmacological treatments used (eyedrops and general); and (c) patient feelings a few minutes before surgery. Patients also shared their impressions regarding the nursing interview and medical examination and provided feedback on doctors' professional conduct. The exact template of the questionnaire is available in the additional materials (Supplement).

\section{Statistical Analysis}

Survey data were analyzed and verified using the statistical program R, version 3.5.4. Answers to individual questions were mostly qualitative, and these qualitative variables were expressed as frequencies and percentages of each answer. The normality of the distribution of quantitative variables was verified using the Kolmogorov-Smirnov test. Given the absence of normal distributions, the quantitative variables were expressed as frequencies, means, standard deviations, and medians. Comparisons between patients undergoing either their first- or second-cataract surgeries were performed using the chi-squared test, Fisher's exact test (when the number of subgroups did not allow for the use of the chi-squared test), and the Mann-Whitney $U$-test. Some questions were designed to provide more than two possible answers. When the two groups showed a statistically significant difference in the structure of responses, an additional series of chi-squared post hoc tests were performed to identify the exact answers causing the difference between the two groups. 
Considering the quantitative nature of the data (the number of negative and positive elements) and the lack of both a normal distribution and equivalence between the compared groups, non-parametric tests were used in the statistical analyses. Specifically, the Mann-Whitney U and Kruskal-Wallis tests were employed for comparing two or more than two groups, respectively. A $P$-value less than 0.05 was considered to be statistically significant.

\section{Results}

A total of 200 consecutive patients ( 81 men and 119 women) aged 42 to 89 years (median age, 72 years) were enrolled in this study. Patients were divided into either group I or group II, which included patients undergoing either their first surgery for cataracts or their second-cataract surgery for their other eye, respectively. Patients' demographic characteristics and concomitant diseases are recorded in Table 1. Statistically significant intergroup differences in assessed features were not observed $(P>0.05)$, except for in the incidence of thyroid diseases $(P=0.034)$.

Patients' subjective feelings during the preoperative period are shown in Table 2.

The admission procedures were described as efficient and problem-free by $81.4 \%$ and $93.4 \%$ of patients in groups I and II, respectively $(P=0.031)$. A detailed assessment of patients' evaluation of the admission procedures is shown in Table 3.

With regards to patient assessment of the medical examination on the day of surgery, the groups differed significantly only with respect to the accuracy of the examination $(P=0.047)$. Detailed data are shown in Table 4. Negative opinions related to the medical examination did not differ significantly between the groups and were expressed by only a few respondents (Table 5).

Significant differences in patients' perception of satisfactory information provision pertaining to the operation and accompanying complications were seen in both groups. Specifically, $79.8 \%$ and $68.4 \%$ of patients from groups I and II, respectively, considered the information received about the course of the procedure to be satisfying $(P=0.003)$. Both groups also differed in their perceptions of the provision of information regarding complications $(P=0.039)$, with 35 patients in group I $(28.2 \%)$ and 16 patients in group II $(21 \%)$ not understanding or only partially understanding this information. In addition, $75 \%$ and $65.7 \%$ of patients in groups I and II, respectively, were not aware at which point in time the intraocular lens measurement would be performed during the
Table I Patient Demographic and Clinical Characteristics

\begin{tabular}{|c|c|c|c|}
\hline Characteristics & $\begin{array}{l}\text { Group I } n= \\
\text { I } 24\end{array}$ & $\begin{array}{l}\text { Group II } \\
n=76\end{array}$ & P-value \\
\hline \multicolumn{4}{|l|}{ Gender } \\
\hline Male & $50(40.3 \%)$ & $31(40.8 \%)$ & $>0.999$ \\
\hline Female & 74 (59.7\%) & 45 (59.2\%) & \\
\hline Mean age $\pm S D$ (years) & $72.7 \pm 11.0$ & $72.5 \pm 11.0$ & 0.985 \\
\hline Male & $71.8 \pm 11.2$ & $69.8 \pm 12.2$ & 0.616 \\
\hline Female & $73.2 \pm 10.9$ & $74.3 \pm 9.9$ & 0.493 \\
\hline \multicolumn{4}{|l|}{ Education } \\
\hline Primary & $16(12.9 \%)$ & 21 (27.6\%) & \\
\hline Vocational & $33(26.6 \%)$ & $20(26.3 \%)$ & 0.062 \\
\hline Middle & $58(46.8 \%)$ & $25(32.9 \%)$ & \\
\hline Higher & $17(13.7 \%)$ & $10(13.2 \%)$ & \\
\hline Currently employed & $17(13.7 \%)$ & $12(15.8 \%)$ & 0.528 \\
\hline Out of work or retired & 107 (86.3\%) & $64(84.2 \%)$ & \\
\hline \multicolumn{4}{|l|}{ Type of employment* } \\
\hline $\begin{array}{l}\text { Intellectual labor } \\
\text { (white-collar) }\end{array}$ & $49(39.5 \%)$ & $21(27.6 \%)$ & 0.070 \\
\hline $\begin{array}{l}\text { Manual labor (blue- } \\
\text { collar) }\end{array}$ & $63(50.8 \%)$ & $40(52.6 \%)$ & \\
\hline Never in employment & $12(9.7 \%)$ & $15(19.7 \%)$ & \\
\hline \multicolumn{4}{|l|}{ Area of residence } \\
\hline City & $52(41.9 \%)$ & $29(38.2 \%)$ & 0.597 \\
\hline $\begin{array}{l}\text { Small- or mid-sized } \\
\text { town }\end{array}$ & $47(37.9 \%)$ & $27(35.5 \%)$ & \\
\hline Rural area & 25 (20.2\%) & $20(26.3 \%)$ & \\
\hline Smokers & $54(43.5 \%)$ & $43(56.6 \%)$ & 0.333 \\
\hline \multicolumn{4}{|l|}{ Illnesses } \\
\hline Hypertension & 95 (84.1\%) & $54(79.4 \%)$ & 0.479 \\
\hline Diabetes & 75 (66.4\%) & $4 \mathrm{I}(60.3 \%)$ & 0.446 \\
\hline $\begin{array}{l}\text { Cardiovascular } \\
\text { diseases }\end{array}$ & 51 (45.1\%) & $31(45.6 \%)$ & $>0.999$ \\
\hline Pulmonary diseases & $26(23.0 \%)$ & $12(17.6 \%)$ & $0.47 \mid$ \\
\hline Osteoarthritis & 21 (I8.6\%) & $15(22.1 \%)$ & 0.756 \\
\hline Cancer & 5 (4.4\%) & $3(4.4 \%)$ & $>0.999$ \\
\hline Thyroid diseases & $4(3.5 \%)$ & $9(13.2 \%)$ & 0.034 \\
\hline Urinary tract diseases & $2(1.8 \%)$ & $2(2.9 \%)$ & 0.636 \\
\hline
\end{tabular}

Notes: Values are presented as number of patients (percentage); *Current or before retirement.

Abbreviation: SD, standard deviation.

ophthalmological examination $(P=0.420)$. Finally, $37.1 \%$ and $53.9 \%$ of patients in groups I and II, respectively, denied receiving an explanation about the type of lens used and its working mechanism $(P=0.031)$.

Twenty patients in group I and nine patients in group II received either tablets or intravenous infusions before surgery based on their individual clinical conditions. These patients were given drugs to reduce intraocular pressure (16 
Table 2 Patient-Reported Feelings During the Preoperative Period

\begin{tabular}{|l|l|l|l|l|l|}
\hline \multirow{2}{*}{} & \multicolumn{2}{|l|}{ Group I } & \multicolumn{2}{l|}{ Group II } & P-value \\
\cline { 2 - 6 } & $\mathbf{n}$ & $\%$ & $\mathbf{n}$ & $\%$ & \\
\hline $\begin{array}{l}\text { Anxiety } \\
\text { Considering abandoning the } \\
\text { operation }\end{array}$ & 69 & 55.7 & 26 & 34.2 & 0.005 \\
$\begin{array}{l}\text { Awareness of the risk of } \\
\text { complications }\end{array}$ & 92 & 74.2 & 54 & 71.1 & 0.765 \\
$\begin{array}{l}\text { Patience } \\
\text { Impatience }\end{array}$ & 82 & 66.1 & 53 & 69.7 & 0.78 \\
Anger and frustration & 14 & 11.3 & 7 & 9.2 & 0.04 \\
\hline
\end{tabular}

Table 3 Patient Evaluation of Admission Procedures

\begin{tabular}{|l|l|l|l|l|l|}
\hline & \multicolumn{2}{|l|}{ Group I } & \multicolumn{2}{|c|}{ Group II } & P-value \\
\cline { 2 - 6 } & $\mathbf{n}$ & $\%$ & $\mathbf{n}$ & $\%$ & \\
\hline $\begin{array}{l}\text { Efficient and problem-free } \\
\text { admission process } \\
\begin{array}{l}\text { Satisfaction with nursing } \\
\text { interview }\end{array}\end{array}$ & 100 & 81.4 & 71 & 93.4 & 0.005 \\
$\begin{array}{l}\text { Nursing interview considered } \\
\text { either lengthy or short } \\
\text { Lack of nurse support }\end{array}$ & 38 & 30.6 & 16 & 21.1 & 0.765 \\
\hline
\end{tabular}

Table 4 Patient Assessment of the Medical Examination on the Day of Surgery

\begin{tabular}{|l|l|l|l|l|l|}
\hline \multirow{2}{*}{} & \multicolumn{2}{|l|}{ Group I } & \multicolumn{2}{l|}{ Group II } & P-value \\
\cline { 2 - 6 } & $\mathbf{n}$ & $\%$ & $\mathbf{n}$ & $\%$ & \\
\hline Accuracy of the examination & 82 & 66.1 & 61 & 80.3 & 0.047 \\
Examination was gentle & 100 & 80.6 & 71 & 93.4 & 0.83 \\
Painless & 112 & 90.3 & 68 & 89.4 & 0.65 \\
Duration was appropriate & 101 & 81.4 & 61 & 80.2 & 0.56 \\
\hline
\end{tabular}

Table 5 Negative Opinions Related to the Medical Examination

\begin{tabular}{|l|l|l|l|l|}
\hline \multirow{2}{*}{ Variables } & \multicolumn{2}{|l|}{ Group I } & \multicolumn{2}{l|}{ Group II } \\
\cline { 2 - 6 } & $\mathbf{n}$ & $\%$ & $\mathbf{n}$ & $\%$ \\
\hline What are your thoughts on the medical examination? \\
\hline It was brief & 20 & 16.1 & 7 & 9.2 \\
It was painful & 2 & 1.6 & $\mathrm{I}$ & 1.3 \\
Medical examination was too long & 4 & 3.2 & 3 & 3.9 \\
Medical examination was too short & 3 & 2.4 & 0 & 0 \\
Doctor did not show any support & 7 & 5.6 & 3 & 3.9 \\
Doctor did not explain properly & $\mathrm{I}$ & 0.8 & $\mathrm{I}$ & 1.3 \\
\hline
\end{tabular}

patients) or overall blood pressure (11 patients) or cough suppressants (two patients). However, over a third of respondents (18.1\% from group I and $17.1 \%$ from group II, $P=$ 0.620 ) did not know the purpose of these additional drugs.

Complaints related to repeated administration of eye drops before surgery did not differ significantly between the two groups. Ninety-one patients in group I (71.4\%) and 52 patients in group II (68.4\%) found these drops to be unpleasant and associated them with symptoms like burning, stinging, or a foreign-body sensation $(P=0.553)$. Twelve patients in both groups $(9.7 \%$ and $15.8 \%, P=$ 0.286 ) perceived the preoperative eye drops to be highly unpleasant, while 28 patients from group I (22.6\%) and seven from group II $(9.2 \%)$ reported them to be very annoying $(P=0.026)$.

\section{Discussion}

We aimed to compare the subjective feelings and opinions related to cataract surgery in patients undergoing either firstor second-eye cataract surgeries. Both groups of patients answered questions about their feelings during the preoperative period, especially their perceptions of the procedures and tests performed right before the surgery. The predominant negative feelings before cataract surgery were fear and anxiety, which were more common in patients undergoing the operation for the first time (55.7\% vs $34.2 \%)$. Similarly, fear of surgery resulted in a third of patients in group I (ie, more than twice the corresponding proportion in group II) considering withdrawing from the surgery during the day before. Thus, secondeye surgery was associated with a significantly lower sense of anxiety, which could be attributed to patient familiarity with the surgery. Positive experiences associated with the first surgery reduced fear before the second eye procedure.

In accordance with our findings, previous studies $^{2,3,7,10-12}$ have reported that patients tend to be generally more relaxed and less nervous before secondeye cataract surgeries. However, all patients in our study experienced significantly heightened anxiety a few minutes before the operation $(69.4 \%$ in group I and $53.9 \%$ in group II). Thus, even positive experiences from previous surgeries cannot completely overcome all psychological barriers, and some anxiety regarding the course or outcome of surgeries will persist.

Most previous studies only assessed anxiety and fear during the preoperative period, often utilizing other diagnostic tools, including electrocardiograms or Holter monitors. ${ }^{8,9}$ In contrast, our data provided a very accurate and detailed 
analysis of patient feelings throughout the preoperative period. Our approach allowed for the identification of the exact elements and procedures that were burdensome and unpleasant for patients, as well as the areas needing improvement. Although hospital admission procedures were most often described as "efficient and without a nervous atmosphere," this description occurred significantly more frequently in group II than in group I (93\% vs $82 \%)$. This difference could be attributed to experience, ie, patients waiting for second-eye surgery were mentally better prepared and better oriented to the procedures that would be performed (ie, blood pressure measurement, administration of intravenous needle, etc.).

We also found that nursing and medical examinations were assessed differently by patients. Although patients usually rated both of these aspects as good, a few patients (6\%) undergoing surgery in group I considered the nurses' support to be insufficient. Additionally, some patients reported the medical examination to be a difficult experience, describing it as brief, painful, too long, or too short. Additionally, patients' expectations about the accuracy of the presurgical medical examination varied between groups, with only $66 \%$ of patients undergoing first-eye operations finding the testing to be sufficiently accurate, whereas $80 \%$ of those undergoing second-eye examinations were satisfied with the test. Given that a qualification visit (ie, a very detailed physical and ophthalmology examination) was performed at our clinic prior to the ophthalmological examination on the day of surgery, further ophthalmological assessments were considered unnecessary. Our results suggest that patients undergoing their second-eye operations found both the medical and nursing procedures to be satisfactory.

Surprisingly, $75 \%$ and $65.7 \%$ of patients in groups I and II, respectively, did not know when the intraocular lens (IOL) was measured during the ophthalmological examination. To the question, "Has it been explained to you what type of lens will be implanted and how does it work?", $37.1 \%$ and $53.9 \%$ of the patients in groups I and II, respectively, responded negatively. It seems particularly strange that more than half of patients in group II were unaware of the lens they would receive, a finding that may be attributable to the fact that it was assumed that the patient had already been informed during preparation for their first surgery. Additionally, only monofocal or toric lenses financed by the National Health Fund are implanted at our university hospital, and other types of lenses, especially the more expensive ones, cannot be implanted. Considering the lack of patient choice, informing them about factors that are not negotiable, including the type of IOL, may seem unnecessary to some providers.

Both a lack of a thorough understanding of the procedure and inaccurate information from doctors have been shown to negatively affect the entire cataract treatment process. ${ }^{7,9}$ Furthermore, a preoperative discussion with the doctor about visual sensations that accompany cataract surgery has been shown to improve patient understanding about the events during the surgery and to significantly reduce preoperative anxiety. This will, in turn, positively affect the course of treatment. ${ }^{13,14}$ Involving nurses in this process may also reduce fear of surgery. As previous research has shown, nursing interventions (eg, instructing and explaining the procedure to patients) can be helpful for reducing anxiety and increasing patient satisfaction. ${ }^{15}$ Accordingly, including nurses as an integral part of the preoperative process should be considered.

Deterioration of vision as a result of possible intraoperative or postoperative complications is always discussed with patients as part of the informed consent process, which can intensify anxiety. Generally, the extent of knowledge that a person needs before he or she agrees to a procedure can vary across patients. Despite the undoubted advantages of adequate education, it has been shown that many patients do not require or desire a large amount of information, arguing that too much knowledge only leads to the intensification of preoperative anxiety and stress. ${ }^{16}$ In general, it has been shown that patients prefer oral to written information, and direct contact with a doctor has more positive effects. ${ }^{8}$ Patient preferences for information formats can be summarized as follows: verbal (spoken), 54\%; visual 47\%; and printed, 36\%. ${ }^{17}$

Use of eye drops, which were frequently administered during the preparatory period before surgery, were negatively assessed by most patients. These drops were perceived by some patients from both groups as very annoying (22.6\% and 9.2\% from groups I and II, respectively). A very large number of patients from both groups (71.4\% in group I and $68.4 \%$ in group II) rated the eyedrops and related sensations as extremely unpleasant. The best solution to this issue may be to replace the repeated application of eyedrops with a single intracameral administration of a solution containing two mydriatics and a local anesthetic during surgery. Additionally, this proposed procedure would reduce the time needed to prepare patients for surgery and limit the contact of medical staff with patients' tear secretions during the current difficult epidemiological situation. 
Our study had a significant limitation in that we only compared a group of patients undergoing first-eye cataract operations with another group of patients undergoing second-eye operations; thus, the two groups contained different sets of people. However, both groups were very comparable in terms of demographic and clinical factors, and group II patients had previously undergone operations at our clinic following the same procedures. Also, due to very few similar surveys that were found in the available literature, we believe our research to be necessary and important. Future research should seek to compare the experiences of the same group of patients who underwent the first- and the secondcataract surgery to eliminate between-group differences.

\section{Conclusion}

In conclusion, our study confirmed previous findings of greater anxiety in patients undergoing their first-eye cataract surgery than their second-eye cataract surgery. Though preoperative anxiety appears to be unavoidable, knowledge gained from previous treatments may help reduce it. Furthermore, meaningful and informative preoperative conversations with patients about the course of disease and possible complications are essential. Doctors need to ensure that the information provided has been understood by patients in order to reduce their anxiety. These conversations should include (a) informing patients about who will operate on them (ie, always a specialist, not a resident) and allowing patients to meet these specialists during the qualifying visit; (b) clearly explaining what a cataract is and its removal procedure, including the length of the operation, type of anesthesia provided, possible complications and how often they occur, and the consequences of not undergoing surgery; and (c) informing patients about the type of lenses used, briefly explaining how they work, and possibly showing educational models of them. Installing an LCD display in the waiting room in order to educate patients about the procedure while they wait for their qualifying examination may represent a good option. Specifically, simple and clear information about cataracts and phacoemulsification (eg, how to prepare for it, how to act after surgery) could be provided. This strategy may reduce preoperative stress and improve patient understanding of the operation. In addition, this strategy would allow patients to ask appropriate questions in the ophthalmologist's office related to the preoperative qualification examination.
Finally, we recommend using a solution of two mydriatics and a local anesthetic for intracameral intraoperative injection to obtain mydriasis and intraocular anesthesia.

\section{Data Sharing Statement}

Readers can access the data supporting the conclusions of the study upon an e-mail request from the corresponding author. The names and personal data of the participants cannot be released due to ethical aspects.

\section{Acknowledgments}

We would like to thank Editage (www.editage.com) for English language editing.

\section{Author Contributions}

DE collected data from the patients, JK worked on the main text, ZM reviewed whole article, IO drafted the work and revised it critically for important intellectual content. All authors reviewed whole article and approved the version to be published. All authors contributed to data analysis, drafting or revising the article, have agreed on the journal to which the article will be submitted, gave final approval of the version to be published, and agree to be accountable for all aspects of the work.

\section{Funding}

This research did not receive any specific grant from funding agencies in the public, commercial, or not-forprofit sectors.

\section{Disclosure}

The authors report no conflicts of interest in this work.

\section{References}

1. Panagiotopoulou EK, Ntonti P, Vlachou E, et al. Patients` expectations in lens extraction surgery: a systematic review. Acta Medica Cordoba. 2018;61(4):115-124.

2. Fagerström R. Fear of a cataract operation in aged persons. Psychol Rep. 1993;72(3_suppl):1339-1346.

3. Foggitt PS. Anxiety in cataract surgery: a pilot study. $J$ Cataract Refract Surg. 2001;27:1651-1655.

4. Mitsonis CI, Mitropoulos PA, Dimopoulos NP, et al. Anxiety and depression in cataract surgery: a pilot study in the elderly. Psychol Rep. 2006;99(1):257-265. doi:10.2466/pr0.99.1.257-265

5. Marback R, Temporini E, Kara N. Emotional factors prior to cataract surgery. Clinics. 2007;62(4):433-438. doi:10.1590/S1807-5932200700 0400010

6. Ramirez DA, Brodie FL, Rose-Nussbaumer J, et al. Anxiety in patients undergoing cataract surgery: a pre- and postoperative comparison. Clin Ophthalmol. 2017;11:1979-1986. doi:10.2147/OPTH.S146135 
7. Nijkamp MD, Kenens CA, Dijker AJM, et al. Determinants of surgery related anxiety in cataract patients. $\mathrm{Br} J$ Ophthalmol. 2004;88(10):1310-1314. doi:10.1136/bjo.2003.037788

8. Nijkamp MD, Ruiter RAC, Roeling M, et al. Factors related to fear in patients undergoing cataract surgery: a qualitative study focusing factors associated with the fear and reassurance among patients who need to undergo cataract surgery. Patient Educ Couns. 2002;47 (3):265-272. doi:10.1016/S0738-3991(02)00002-2

9. Morrell G. Effect of structured preoperative teaching on anxiety levels of patients scheduled for cataract surgery. Insight. 2001;26:4-9.

10. Pager CK. Randomised controlled trial of preoperative information to improve satisfaction with cataract surgery. $\mathrm{Br} J$ Ophthalmol. 2005;89:10-13.

11. Yu JG, Ye T, Huang Q, et al. Comparison between subjective sensations during first and second phacoemulsification eye surgeries in patients with bilateral cataract. J Ophthalmol. 2016. doi:10.1155/ 2016/6521567.

12. Adatia FA, Munro M, Jivraj I, et al. Documenting the subjective patient experience of first versus second cataract surgery. $J$ Cataract Refract Surg. 2015;41(1):116-121. doi:10.1016/j. jcrs.2014.04.041
13. Haripriya A, Tan CSH, Venkatesh R, et al. Effect of preoperative counseling on fear from visual sensations during phacoemulsifications under topical anesthesia. J Cataract Refract Surg. 2011;37 (5):814-818. doi:10.1016/j.jcrs.2010.11.041

14. Voon L-W, Au Eong K-G, Saw S-M, et al. Effect of preoperative counseling on patient fear from the visual experience during phacoemulsifications under topical anesthesia: multicenter randomized clinical trial. J Cataract Refract Surg. 2005;31(10):1966-1969. doi:10.1016/j.jcrs.2005.03.059

15. Gong D, Liu J, Zhao X, et al. The effect of nursing intervention on preoperative cataract. Medicine. 2018;97(42):42. doi:10.1097/ MD.0000000000012749

16. Pager CK, Med B, Dip E, et al. Surgeons' perceptions of their patients` priorities. J Cataract Refract Surg. 2004;30(3):591-597. doi:10.1016/S0886-3350(03)00671-0

17. Tan JF, Tay LK, Mg LH. Video compact discs for patient education: reducing anxiety prior to cataract surgery. Insight. 2005;30:16-21.
Clinical Ophthalmology

\section{Publish your work in this journal}

Clinical Ophthalmology is an international, peer-reviewed journal covering all subspecialties within ophthalmology. Key topics include: Optometry; Visual science; Pharmacology and drug therapy in eye diseases; Basic Sciences; Primary and Secondary eye care; Patient Safety and Quality of Care Improvements. This journal is indexed on PubMed

Submit your manuscript here: https://www.dovepress.com/clinical-ophthalmology-journal
Dovepress

Central and CAS, and is the official journal of The Society of Clinical Ophthalmology (SCO). The manuscript management system is completely online and includes a very quick and fair peer-review system, which is all easy to use. Visit http://www.dovepress.com/ testimonials.php to read real quotes from published authors. 